\title{
Cancer: Personal, Professional, and Practice Impact
}

\author{
Asha Ramsakal, D.O. ', Varisa Lall Dass, J.D. ${ }^{2}$, and Vadin Lall Dass, M.D. ${ }^{3}$ \\ ${ }^{1}$ H. Lee Moffitt Cancer Center, Tampa, FL, USA; ${ }^{2}$ College of Law, Stetson University, Gulfport, FL, USA; ${ }^{3}$ James A Haley VA Hospital, Tampa, FL, USA.
}

J Gen Intern Med 35(4):1300-1

DOI: $10.1007 / \mathrm{s} 11606-019-05374-\mathrm{z}$

(c) Society of General Internal Medicine 2019

\section{PERSONAL}

I remember the day vividly, a curse of my photographic memory. I had "tucked" my husband into pre-op and waited until he was whisked away for his 7-year overdue screening colonoscopy before proceeding with patient rounds. After I had seen two patients, I heard an overhead page, "Dr. Ramsakal please report to endoscopy!" I had an immediate "Takotsubo" moment, expecting a subsequent code blue announcement on my quantum leap to the endoscopy suite. The gastroenterologist calmly proceeded to show me the large, friable colorectal mass while my husband was still under anesthesia. I just shook my head in the affirmative. Dazed, my thoughts raced ahead; staging CTs, port placement, "sandwich" chemo/immune therapy, colon resection plus or minus colostomy, concomitant 5FU/leucovorin plus XRT to the surgical bed to prevent reoccurrence, etc. Then, of course, the turmoil of emotions kicked in. I tried to find a quiet corner at the nurse's station before the tears started gushing. Whom should I call first? The logical answer was our son, the physician; he would offer some calm to this storm despite being a young father of a 6-day-old first child.

While my husband was still a bit groggy under the influence of the midazolam, I sat on the bed, held his hand, and proceeded to give him the news. He nodded an understanding and acceptance. We were high school sweethearts, married for 33 years, and had great faith. We felt we were prepared to battle this and accept the outcome.

The big picture was fuzzy, and I was no artist. Our oncologist kept repeating, "We're going for a cure." But I knew, despite the best current evidence-based care, the 5-year survival was about $25 \%$. Within 2 weeks of diagnosis, my husband had completed his staging CT scans with biopsies of liver mets, fiducial placement, Mediport placement, and oncologic, colorectal, hepatic surgical consultations and got his first dose FOLFIRI/bevacizumab (he had the k-ras mutation). It was a medical whirlwind, but what kept us going was focusing on the next step.

I understand how our cancer patients feel; navigating the healthcare industry, even with health insurance, is challenging

Received May 28, 2019

Accepted September 12, 2019

Published online November 1, 2019 and frustrating. Patients develop progressive disease that may become incurable, or even fatal, while they attempt to schedule appointments for Mediports, physician visits, preauthorization for therapy, and surgeries. It is a reality that you are only aware of when on the other side of the stethoscope.

But truthfully, it was the "smaller" challenges that proved to be more difficult. We developed creative ways to secure colostomy wafers and decrease stool leakage. We discovered that sticky white rice and marshmallows ingested $30 \mathrm{~min}$ before colostomy bag switches decreased watery stool production during this process. I used this as an opportunity to upgrade my 15-year-old washer and dryer. The new pair had a steam sanitizer and antibacterial cycle so I could sanitize stool-covered laundry. Instructing patients and families on bleaching all contact surfaces to terminate Clostridium difficile endospores had a new meaning to us when he developed pseudomembranous colitis after his jejunostomy reversal. By the way, he failed both oral metronidazole and vancomycin but responded to fidaxomicin (this was in 2016). I smiled and felt a secret vindication when I saw the IDSA 2017 guidelines recommend fidaxomicin as one of the first-line therapies for $C$. difficile and removed metronidazole.

\section{PROFESSIONAL}

My cancer experience and the obvious "double-standard" in care not only between insured patients on both sides of the healthcare industry but also between insured and the uninsured was the primary driver in my decision to change career paths. I felt I could have the greatest impact in healthcare disparity if I worked in an academic tertiary cancer center.

My professional goals are now focused on developing strategies not only to increase access of all patients to cancer care but also to brainstorm ways to solve the shortcomings in our current delivery of healthcare to cancer patients. As the Chair of Medicine at a US News and World Report Top 10 Cancer Center, I am fortunate to have a whole team assisting with this effort. I am encouraging (more like demanding) my medical colleagues to embrace the culture of increased patient access to care in ways in which I have direct influence. I see the pendulum shifting in our Urgent Care, where we manage complications of cancer therapy, to a more "open" rather than "referral only-based" model. Our Urgent Care Center is now partially staffed by emergency medicine-trained physicians. They have not only facilitated an increase in the quality and volume of patient care but can also perform necessary diagnostic and therapeutic procedures such as thoracenteses, paracenteses, lumbar punctures, and central lines 
to more efficiently and effectively manage complications of cancer, filling some of the current "holes" in coverage by our current hospital staffing. This will expedite downtime between the necessary therapy patients require to prevent disease progression or facilitate remission. I have been dedicated in working with other leaders of the cancer center to provide physician support and leadership to a code blue team at one of our ambulatory centers so we can initiate designated patient clinical trials that require this support. I am also committed to recruitment of additional medicine-based provider staffing of inpatients, increasing patient-provider ratios if necessary and implementing backup patient coverage processes to avoid postponement of scheduled inpatient chemotherapy in high census periods.

From a broader perspective, there are explicit changes in medical care that must evolve to equilibrate the different standards of care. Some cancer hospitals are exempt from the Prospective Payment System (PPS-Exempt) by the Centers for Medicare and Medicaid Services (CMS) but, in FY 2021, would be penalized for 30-day unplanned readmissions. In order to increase newly diagnosed cancer patients' access to healthcare (independent of patient funding), there should be the development of CMS quality measures based on time to first appointment from first patient contact. Eligibility to participate should also include "virtual visits" with a provider (physician or extended provider). Successful attainment of this measure could then be used by all healthcare systems (PPS or non-PPS-Exempt) to nullify another CMS measure that was subthreshold. This reciprocity would certainly incentivize participation with a win-win for both patients and the healthcare industry. The latter should be tasked with the development of a patient-centric "index of acuity" where one of the most heavily weighted components is prognosis based on malignancy type and stage. The time to first appointment should be inversely proportional to the "index of acuity."

The dichotomy of care between the insured and uninsured could also be more aligned if we had federally funded universal healthcare for everyone, leaving private insurance optional.

\section{PRACTICE}

Personally, I found myself having a new outlook in taking care of my cancer patients. I have changed my behavior, making a conscious effort to always sit close to the bedside or on the bed and doing the "double clasp sandwich" handshake with patients and family members. I am allowing patient and family quality of life to supersede institutional and national metrics when there is a conflict. I spend more time counseling, stressing to stay the course, think about the next step in treatment, live in the moment, and spend as much time with family members. I even feel comfortable sharing my experience to increase the physician-patient and physician-house staff bond.

I will continue to teach medical students and residents to embrace my new philosophy. As attendings, we have the ability to mold young minds to be their best, mentor them to treat all patients equally, and encourage them to volunteer at free healthcare clinics even if the American College of Graduate Medical Education does not mandate this. I stress to my young house staff and physician mentees that when they are discontent about doing an extra admission or picking up an extra patient, reflect on the altruistic care that they would expect if in that patient's situation.

Cancer has inspired my family to exceed their comfort level. My husband ironically did not start to lead singing at our church until after his extensive lung surgeries. Our daughter, an attorney by training and a reporter by heart, who does not have a medical bone in her body did a story on CAR-T immunotherapy.

My husband has had no evidence of disease reoccurrence in almost 4 years from his initial diagnosis. He has lived to witness and adore his second grandson, his namesake, and wrestle with his first with renewed strength.

Time not only heals wounds but also alters our behavior. Whenever I see myself relapsing into my previous habit of quantity before quality during rounds, I remember my experience. Then, I open the patient's door, see my family in the room, and look into the rear view mirror.

Corresponding Author: Asha Ramsakal, D.O.; H. Lee Moffitt Cancer Center, Tampa, FL, USA (e-mail: Asha.Ramsakal@moffitt.org).

\section{Compliance with Ethical Standards:}

Conflict of Interest: The authors declare that they do not have a conflict of interest. 